\title{
UM POSSÍVEL DIÁLOGO ENTRE A ESCOLA DOS ANNALES \& A ANÁLISE DE CONTEÚDO EM PESQUISAS HISTÓRICAS
}

\section{A POSSIBLE DIALOGUE BETWEEN THE SCHOOL OF THE ANNALS \& ANALYSIS OF CONTENT IN HISTORICAL RESEARCH}

\section{Fabrícia Carla de Albuquerque Silva ${ }^{1}$ Elione Maria Nogueira Diógenes ${ }^{2}$ Deyvid Braga Ferreira ${ }^{3}$}

\section{RESUMO:}

O questionamento que norteia este artigo pode ser assim delineado: Como dialogam a Escola dos Annales e a Análise de Conteúdo em pesquisas de caráter histórico? A partir dessa questão, a estrutura narrativa traz aproximações epistemológicas entre ambas as escolhas metodológicas e tece problematizações relativas às desconfianças e resistências no entorno das mesmas. O texto resulta de uma pesquisa bibliográfica, na qual, foram consultados estudiosos que tratam da Interdisciplinaridade, Pesquisa em Educação, Análise de Conteúdo, Método e Teorias Históricas. A discussão compreendeu: o lugar da pesquisa histórica e/ou historiográfica; Escola dos Annales e Análise de Conteúdo nas pesquisas qualitativas e a busca do implícito nas fontes. Por fim, o estudo sublinhou possibilidades de diálogo entre Escola

${ }^{1}$ Doutoranda em Educação - PPGE/CEDU/ UFAL, Membro do Grupo de Pesquisa Estado, Políticas Sociais e Educação Brasileira (GEPE), Mestre em Educação - PPGE/CEDU/ UFAL, Graduada em Pedagogia pela Universidade Federal de Alagoas. E-mail: fabriciacarla2007@hotmail.com

${ }^{2}$ Formada em História pela Universidade Federal do Ceará. Doutora em Políticas Públicas pela Universidade Federal do Maranhão; Professora dos cursos de Graduação e Pósgraduação no CEDU/UFAL; Líder do Grupo de Pesquisa Estado, Políticas Sociais e Educação Brasileira (GEPE). E-mail: elionend@uol.com.br

${ }^{3}$ Doutorando em Linguística, na Linha de Pesquisas acerca do Discurso: Sujeito, História e Ideologia (PPGLL/FALE/UFAL - 2020.01). Mestre em Educação - PPGE/CEDU/UFAL, Membro do Grupo de Pesquisa Estado, Políticas Sociais e Educação Brasileira (GEPE), Professor da FAT/AL. E-mail: deyvidbrafe@bol.com.br 
dos Annales e Análise de Conteúdo, diferenciando-as, respectivamente, enquanto abordagem metodológica e as técnicas de análise de dados. Apesar de se apontar a possível hierarquia entre abordagem metodológica e técnicas de análise, entretanto, nesse texto, opõe-se à hierarquia entre ciências, bem como, ao engessamento das formas de se fazer pesquisa.

PALAVRAS-CHAVE: Pesquisas históricas. Escola dos Annales. Análise de Conteúdo. Métodos e Teorias Históricas.

\section{ABSTRACT:}

The question that guides this article can be outlined as follows: How do the Escola dos Annales and Content Analysis dialogue in historical research? Based on this issue, the narrative structure brings epistemological approaches between both methodological choices and weaves problematizations related to mistrust and resistance around them. The text is the result of a bibliographic research, in which scholars were consulted dealing with Interdisciplinarity, Research in Education, Content Analysis, Method and Historical Theories. The discussion included: the place of historical and / or historiographical research; Annales School and Content Analysis in qualitative research and the search for the implicit in sources. Finally, the study highlighted possibilities for dialogue between Escola dos Annales and Content Analysis, differentiating them, respectively, as methodological approach and data analysis techniques. Although the possible hierarchy between methodological approach and analysis techniques is pointed out, however, in this text, it is opposed to the hierarchy between sciences, as well as to the plastering of the ways of doing research.

KEYWORDS: Historical research. School of the Annals. Content analysis. Methods and Historical Theories.

As doze pedras que tiraram do Jordão, levantando-as Josué em coluna em Gilgal. E disse aos filhos de Israel: Quando, no 
futuro, vossos filhos perguntarem a seus pais, dizendo: Que significam estas pedras? Fareis saber a vossos filhos, dizendo: Israel passou em seco este Jordão. (BÍBLIA SAGRADA. Josué 4. 20-22).

\section{O LUGAR DA PESQUISA HISTÓRICA E/OU HISTORIOGRÁFICA}

$\mathrm{Na}$ epígrafe inicial, do texto, sinaliza-se o uso de pedras como memorial de um milagre vivenciado por Israel, isto é, estabelecimento de vestígios acerca do que não se desejava esquecer... E, em meio ao contexto das pesquisas acadêmicas, o que se tem colocado em evidência? O que não se deseja esquecer? As pesquisas, independente da tipologia, são igualmente valorizadas?

Há abordagens epistemológicas que questionam a validade das Ciências Sociais, tendo em vista que estas se opõem à concepção de neutralidade, além de considerar a subjetividade nas pesquisas. Isto é, tanto o pesquisador quanto o "objeto de pesquisa" são sujeitos históricos. E, dentro dessa discussão, há aqueles de consideram as ciências sociais “inferiores” às ciências naturais.

Porém, isso é uma ideologia, pois na ciência histórica nada é inferior "a", tendo em vista que "o homem é, ao mesmo tempo, Razão e Imaginação" (JAPIASSU, 1986, p. 68). Nessa perspectiva, parafraseia-se Monteiro et al $(2012$, p. 2): e por mais objetivo que sejam as reflexões sobre a ciência estão repletas de poesia e subjetividade e, por sua vez, o olhar sobre pesquisas históricas guarda sempre a curiosidade científica do pesquisador.

Entretanto, há, uma hierarquização do saber, que pode, inclusive, ser observada ao se tratar de pesquisas em Educação. Há discussões acadêmicas, cujas entrelinhas ou omissões discursivas apontam para a classificação do que se considera como "mais" ou "menos" importante nas 
pesquisas educacionais; por exemplo: Estudar problemáticas relativas a épocas anteriores à Contemporaneidade seria válido?

A este respeito é significativo observar o questionamento de March Bloch (2001, p. 64): “O que diríamos de um físico que, contentando-se em enumerar os miriâmetros, estimasse a ação da Lua sobre o nosso globo mais considerável do que a do Sol?”. A partir dessa indagação, Bloch (2001, p. 65) traz a reflexão de que "a eficácia de uma força não se mede exatamente por sua distância", ou seja, não se pode afirmar que a Lua é mais significativa para a Terra em virtude de sua maior aproximação.

De forma semelhante, não se deve considerar "inútil” determinado acontecimento apagado no tempo ou afastado do presente; e nem como impedimento para a sua compreensão. O duplo olhar - passado e presente tem uma relação de complementaridade, rumo à inteligibilidade, como destaca Bloch (2001, p. 65): “A incompreensão do presente nasce fatalmente da ignorância do passado. Mas talvez não seja menos vão esgotar-se em compreender o passado se nada se sabe do presente".

Sublinhar a relevância de pesquisas históricas e/ou historiográficas, nos Programas de Pós-Graduação, não diz respeito à tentativa do Historicismo-conversador em colocar a História num palanque mais elevado em relação às demais ciências... Melhor do que hierarquizar as ciências, temáticas de pesquisa e/ou abordagens teórico-metodológicos, é observar os critérios de qualidade de produção científica. Quais os critérios lógicos e epistemológicos foram utilizados para se verificar a qualidade de determinada pesquisa? - Relevante questionamento, pois, independente da temática a ser investigada, no contexto científico, há a necessidade de elementos de sistematização, em busca das respostas às perguntas norteadoras.

Nesse contexto, é válido destacar que Bloch (2001) defende a necessidade de se fazer pesquisa histórica com o auxílio das demais ciências. Logo, mais significativo do que se disputar status, o diálogo entre as ciências proporciona maior proficuidade na busca por respostas às perguntas norteadores da pesquisa. 
Considerando-se o vínculo entre História e Historiografia, nesse artigo, serão utilizados os dois termos. Todavia, no que diz respeito às suas especificidades, serão consideradas definições de Aróstegui (2006, p. 3), para o qual, História está vinculada a experiência humana em sua vivência temporal; enquanto a Historiografia corresponde à reflexão sobre a natureza do histórico. Logo, as pesquisas históricas e/ou historiográficas compreendem dois elementos inseparáveis: "ser social" e "ser temporal", conforme aponta Arruda (2006, p. 6).

Entretanto, é válido ressaltar que a forma de realizar a pesquisa pode apresentar variações, dependendo da abordagem metodológica em que se está ancorado (Historicismo-positivista, Historicismo-Relativista, Materialismo Histórico, entre outros).

Portanto, para além de "modismos teóricos" e/ou de "ecletismo pragmático", como diria Gamboa (2018, p. 47), com vistas à compreensão e resposta ao questionamento proposto no título do artigo, os tópicos subsequentes têm como cerne: 1. Concepção dos princípios norteadores da "Escola dos Annales" e "Análise de Conteúdo", distinguindo, inclusive, abordagem metodológica e técnica nas pesquisas qualitativas; 2. Aspectos teórico-práticos acerca do trabalho do pesquisador na análise de fontes, dispondo de ferramentas manuais e digitais, além de possibilidades com técnicas de Análises de conteúdo.

\section{ANNALES E ANÁLISE(S) DE CONTEÚDO: abordagem metodológica e técnica(s)}

Ao se tratar de epistemologia histórica, Bachelard e seu discípulo Georges Canguilhem são considerados como referenciais. Para eles, a reflexão crítica sobre a produção de conceitos prescinde de atenção à história das ciências. Assim, na epistemologia histórica de Bachelard, "a ciência é um objeto construído socialmente, cujos critérios de cientificidade são coletivos e setoriais às diferentes ciências" (LOPES, 1996, p.251).

A esse respeito, Monteiro et al (2012, p. 3) afirma que se as ciências "nascem e evoluem em circunstâncias históricas determinadas", o 
extraordinário é descobrir a gênese, a estrutura e o modus vivendi dos conhecimentos científicos. Assim, "o principal objetivo desta epistemologia seria, então, a 'reformulação' do saber científico e a 'reforma' das noções filosóficas" (MONTEIRO et al, 2012, p. 3).

Deste modo, não há uma única forma de se fazer pesquisa histórica. Os historiadores positivistas buscavam a objetividade, o universal, uma visão de "verdade única" e "tendiam a se aproximar ingenuamente das fontes históricas, como se estas fossem mero depósito de informações" (BARROS, 2012, p. 409).

Por outro lado, os historicistas partiam da concepção de que a subjetividade perpassa todas as fontes, há um olhar sobre si e noção de que cada época produz a sua verdade histórica, isto é, buscavam a singularidade. Entretanto, o historicismo não foi um movimento homogêneo, pois, segmentou-se em dois ramos: "historicismo conservador" e "historicismo relativista". De acordo com Barros (2012, p. 408), o primeiro "conserva talvez traços difusos do positivismo" e o segundo compreende que tanto o objeto histórico quanto o próprio historiador são relativos.

Num contexto de críticas e afastamento a determinados aspectos do Positivismo e do Historicismo, surge a Escola dos Annales - corrente histórica fundada na França em 1929, por Lucien Febvre e Marc Bloch. Segundo Barros (2010, p. 83 e p, 84), a relação dos Annales com outros paradigmas pode ser denominado de "oposições interativas", pois, não consiste apenas de oposições, também, há um movimento de “diálogo interativo, produtivo, e por vezes assimilativo".

Dentre as estratégias da Escola dos Annales está a objeção à chamada "História factual", que consistia em "extrair dos documentos os fatos (geralmente políticos) e em ordená-los cronologicamente em uma linha compreensível, frequentemente ancorada em cadeias causais, outras vezes acumulativa de informações nem sempre necessárias”. (BARROS, 2010, p. 92).

Nessa perspectiva, para os annalistas, mais relevante do que uma "história factual", era a "história-problema", que consistia em "reconstruir 
o vivido através de problemas e motivações da época do próprio historiador". Assim, a pesquisa baseada na história-problema deve deixar tudo explícito: “as fontes, os métodos, e mesmo o lugar de onde o historiador se pronuncia [...] também as hipóteses [...]" (BARROS, 2010, p. 93), pois, o fato histórico é consequência de construção do pesquisador, isto é, não está ingenuamente projetado nos documentos.

Outra relevante característica dos annalistas é o diálogo e cooperação entre disciplinas. A esse respeito, é válido ressaltar que March Bloch - um dos fundadores da Escola dos Annales - na obra "Apologia da História ou o Ofício do Historiador" (2001) deixa indícios de defesa acerca da necessidade de diálogo entre História e as diversas ciências sociais (Economia, Sociologia, Geografia, Psicologia...).

Esse aspecto "multidisciplinar" foi, inclusive, destacado por Laurence Bardin (2016, p. 13) como "efervescência" presente nas "correntes culturais francesas". A referida autora fez tal afirmativa ao criticar os limites da Análise de conteúdo anglo-saxônica (Content analysis), face às propostas francesas. Além disto, apresenta (2016, p. 33) a "Análise de conteúdo", ou melhor, "análises de conteúdo" - como ela prefere denominar - enquanto instrumentos que podem ser utilizados por diversos cientistas: sociólogo, psicoterapeuta, historiador, psicólogo, publicista, entre outros.

Esse auxílio das ou para as diversas ciências, mencionado tanto na Escola dos Annales quanto na Análise de Conteúdo de Bardin, remete-nos ao que Sílvio Gallo (1995, p. 9) denomina de paradigma rizomático/ transversal: "uma riqueza geográfica pautada numa lógica do devir, da exploração, da descoberta de novas facetas”. Essa é uma forma de pensar na qual as ciências possuem a possibilidade de interconexão, sem hierarquizar os saberes, ao contrário do paradigma arborescente.

Pensar numa perspectiva rizomática é extrapolar a perspectiva de cópia e reprodução. Isso lembra a afirmativa de Bardin acerca da sua obra "Análise de conteúdo", pois, mesmo enquanto manual, não deve ser tomada como livro de receitas: "a análise de conteúdo não é, esperamo-lo, nem doutrinal nem normativa" (BARDIN, 2016, p. 20), e completa: "Não existe 
coisa pronta em análise de conteúdo, mas somente algumas regras de base, por vezes dificilmente transponíveis. A técnica de análise de conteúdo adequada ao domínio e objetivos pretendidos tem de ser reinventada a cada momento [...]" (BARDIN, 2016, p. 36, grifo nosso).

Afinal, o que é análise de conteúdo? Abordagem metodológica ou técnica? É possível colocá-la em diálogo com uma pesquisa histórica?

Segundo Bardin (2016), atualmente, Análise de Conteúdo pode ser definida da seguinte forma:

Um conjunto de instrumentos metodológicos cada vez mais sutis em constante aperfeiçoamento, que se aplicam a "discursos" (conteúdos e continentes) extremamente diversificados. O fator comum dessas técnicas múltiplas e multiplicadas - desde o cálculo de frequências que fornece dados cifrados, até a extração de estruturas traduzíveis em modelos - é uma hermenêutica controlada, baseada na dedução: a inferência. Enquanto esforço de interpretação, a análise de conteúdo oscila entre os dois polos do rigor da objetividade e da fecundidade subjetiva.” (BARDIN, 2016, p. 15).

Análises de conteúdo não correspondem a abordagens metodológicas, mas são técnicas de pesquisa com a primordial finalidade de inferir. Logo, não se restringem a mera descrição. A inferência corresponde ao procedimento intermediário, que terá fundamental importância no alcance da interpretação e respostas às perguntas de pesquisa.

Há estudiosos que atrelam as Análises de Conteúdo ao Positivismo ou restringem o seu uso às ciências exatas, em virtude de sua origem estar marcada pela busca de distanciamento entre pesquisador e objeto de estudo, além do aspecto de contagem de frequências. Porém, as Análises de conteúdos não se restringem a essa característica. No plano metodológico, há uma dupla abordagem (quantitativa e qualitativa): 
$\mathrm{Na}$ análise quantitativa, o que serve de informação é a frequência com que surgem certas características do conteúdo. $\mathrm{Na}$ análise qualitativa é a presença ou a ausência de uma característica de conteúdo ou de um conjunto de características num determinado fragmento de mensagem que é tomada em consideração. (BARDIN, 2016, p. 27)

A partir do princípio de diálogo entre as diversas ciências, não há incongruência em se utilizar, nas pesquisas das Ciências Sociais, do auxílio de técnicas que trazem características ligadas ao aspecto quantitativo. $\mathrm{O}$ problema de pesquisa é que irá mostrar ao pesquisador se há necessidade de caminhar exclusivamente no viés qualitativo e/ou quantitativo. Portanto, uma pesquisa histórica a qual siga uma abordagem metodológica Historicista - oposta ao Positivismo-, por exemplo, não terá como meta descrever, mas compreender determinada problemática, pois, busca-se o implícito nas fontes. A análise de conteúdo pode ser de significativa valia nesse processo de busca da "presença" e "ausência" nas fontes históricas.

Aróstegui (2006, p. 516) defende que há uma hierarquia entre os pressupostos metodológicos e as técnicas: “As técnicas se compõem de um conjunto de regras comprovadas, redundantes, que estão subordinadas sempre aos princípios metodológicos. As técnicas são o elemento-chave na construção dos dados". [sic]

O referido autor prossegue defendendo que uma mesma técnica pode ser utilizada por diversas ciências e seus métodos de pesquisa, porém, faz uma ressalva de que é necessário "não confundir o que são técnicas normais de quantificação com pressupostos metodológicos quantitavistas, que são duas questões distintas". (ARÓSTEGUI, 2006, p. 517). O quantitativismo parte da ideia de que a quantidade ou relação matemática seria suficiente para explicar a vida social e a vida histórica.

Levando-se em consideração os apontamentos supracitados, pode-se inferir que um pressuposto de natureza qualitativa pode utilizar a seu serviço uma técnica de origem quantitativa. No árduo caminho do processo de 
análise das fontes, inferência e interpretação dos dados, é necessário somar esforços e não criar bifurcações desnecessárias entre pesquisas qualitativas e quantitativas.

\section{BUSCA PELA RADIOGRAFIA DAS FONTES HISTÓRICAS}

Uma fotografia traz o explícito, aquilo que se pode ver; entretanto, fazer uma analogia da análise de fontes com uma radiografia significa a busca pelo implícito, o não dito. Esta é justamente a proposta de Bardin (2016, p. 47 e p. 48) no que concerne à leitura feita pelos analistas de conteúdo das comunicações: "Não se trata de atravessar significantes, para atingir significados, à semelhança da decifração normal, mas atingir através de significantes, ou de significados (manipulados), outros significados de natureza psicológica, sociológica, política, histórica, etc.”.

O processo para chegar à inferência é árduo, detalhado e constituído de três etapas principais na perspectiva de Bardin (2006, p. 125): 1. Préanálise; 2. Exploração de material; 3. Tratamento dos resultados, inferência e interpretação.

Nesse trilhar em busca de inferência e interpretação de fontes, sublinha-se, nesse artigo, a história-problema, a interdisciplinaridade, bem como, a nova concepção acerca do tempo (características alvitradas por March Bloch - fundador da Escola dos Annales). A referida Escola instituiu uma nova forma de fazer Historiografia Ocidental, cuja contribuição transformadora foi abordada por José Carlos Reis no livro "Nouvelle Histoire e Tempo Histórico" (1994).

Em outro campo de reflexão, a expressão "Escola dos Analles" considera os documentos ou as fontes históricas não somente do ponto de vista singular, e sim como partes constituintes de um elo de fontes semelhantes entre si. A série é constituída por fontes homogêneas, comparáveis, cuja apreensão é possível em um espaço de continuidade (temporal ou espacial), permitindo uma abordagem de conjunto. (BARROS, 2010-b, p. 12).

Filos. e Educ., Campinas, SP, v.11, n.2, p.324-341, maio/ago. 2019 - ISSN 1984-9605 
Tal perspectiva está ligada à chamada História Serial-Quantitativa, a qual constituiu-se como "a grande novidade historiográfica trazida pelos Annales", segundo Barros (2010-b, p. 12), cujo impulso predominou nas décadas de 1950 e 1960 e tinha por finalidade "perceber tanto as permanências como as oscilações e variações (por exemplo, em uma determinada sequência de tempo)". (BARROS, 2010-b, p. 13).

A Escola dos Annales se efetivou sob a liderança de Marc Bloch, Lucien Febvre, e Fernando Braudel. Os dois primeiros fizeram parte da primeira geração dos Annales e o terceiro integra a segunda geração do referido movimento. Esses influenciam até os dias atuais, atravessando continuidades e descontinuidades.

Sob a perspectiva de Bloch (2001, p. 79), "os textos ou os documentos arqueológicos, mesmo os aparentemente mais claros e mais complacentes, não falam senão quando sabemos interrogá-los". E completa: "toda investigação histórica supõe, desde seus primeiros passos, que a busca tenha uma direção. No princípio, é o espírito. Nunca [em nenhuma ciência,] a observação passiva gerou algo de fecundo". (BLOCH, 2001, p. 79),

Diante do exposto, a partir de fundamentação na Escola dos Annales e utilizando-se as técnicas de análise de conteúdo, nesse artigo, propõem-se os seguintes quadros como instrumentos para análise, com vistas a contribuir na indagação de fontes e, como diria Bloch, gerar algo fecundo:

\begin{tabular}{|c|c|c|c|c|c|c|c|}
\hline \multicolumn{8}{|c|}{ QUADRO 1: PRÉ-ANÁLISE DAS FONTES DE PESQUISA } \\
\hline $\begin{array}{c}\text { Tipo } \\
\text { de } \\
\text { document } \\
\text { o } \\
\text { (manus } \\
\text { crito, } \\
\text { impresso, } \\
\text { imagem...) }\end{array}$ & $\begin{array}{c}\text { Ond } \\
\text { e foi } \\
\text { localiza } \\
\text { do? }\end{array}$ & $\begin{array}{l}\text { Escr } \\
\text { ito por } \\
\text { quem? }\end{array}$ & $\begin{array}{c}\text { O } \\
\text { autor } \\
\text { pertencia } \\
\text { ao Grupo } \\
\text { de Poder, } \\
\text { Oposição } \\
\text { ou } \\
\text { Movimen } \\
\text { to } \\
\text { popular? }\end{array}$ & $\begin{array}{c}\text { Quan } \\
\text { do foi } \\
\text { escrito/ } \\
\text { publicado } \\
?\end{array}$ & $\begin{array}{c}\mathrm{Pa} \\
\mathrm{ra} \\
\text { quem } \\
?\end{array}$ & $\begin{array}{c}\text { C } \\
\text { om } \\
\text { qual } \\
\text { objeti } \\
\text { vo? }\end{array}$ & $\begin{array}{c}\text { Códig } \\
\text { o do } \\
\text { Documen } \\
\text { to } \\
\text { (Criado } \\
\text { pelos } \\
\text { pesquisador } \\
\text { es) }\end{array}$ \\
\hline & & & & & & & \\
\hline
\end{tabular}




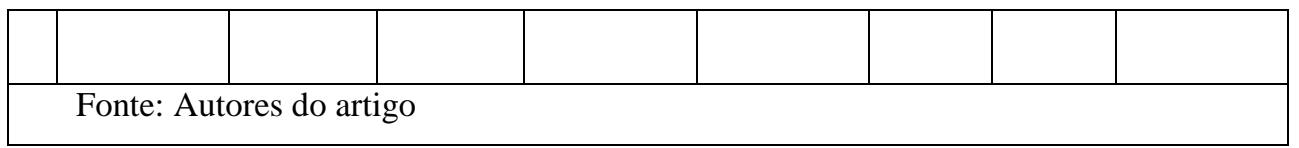

\begin{tabular}{|c|c|c|c|c|c|c|c|}
\hline \multicolumn{8}{|c|}{ QUADRO 2: EXPLORAÇÃO DO MATERIAL E DEFINIÇÃO DE CATEGORIAS } \\
\hline $\begin{array}{c}\text { Códi } \\
\text { go do } \\
\text { Docume } \\
\text { nto }\end{array}$ & $\begin{array}{r}\text { Cate } \\
\text { gorias } \\
\quad a \\
\text { priori }\end{array}$ & $\begin{array}{l}\text { Palavr } \\
\text { as mais } \\
\text { citadas } \\
\text { (frequênc } \\
\text { ias) }\end{array}$ & $\begin{array}{c}\text { Trech } \\
\text { os } \\
\text { relevantes } \\
\text { ligados a } \\
\text { cada } \\
\text { palavra }\end{array}$ & $\begin{array}{r}\text { Cate } \\
\text { gorias } \\
\text { interme } \\
\text { diárias }\end{array}$ & $\begin{array}{c}\text { Cate } \\
\text { gorias } \\
\quad a \\
\text { posterio } \\
\quad r i\end{array}$ & $\begin{array}{c}\text { Aut } \\
\text { ores } \\
\text { que } \\
\text { tratam } \\
\text { das } \\
\text { categori } \\
\text { as finais }\end{array}$ & $\begin{array}{r}\text { Infe } \\
\text { rências } \\
\text { do(a) } \\
\text { pesquis } \\
\text { ador(a) }\end{array}$ \\
\hline & & & & & & & \\
\hline & & & & & & & \\
\hline
\end{tabular}

Fonte: Autores do artigo

A pré-análise, proposta no primeiro quadro, traz elementos para uma espécie de caracterização do cenário de criação do vestígio localizado: tipo de documento, atores e relações de forças, inicialmente detectadas. Nessa matriz, atentou-se para a forma do vestígio. No segundo quadro, a ênfase está nas entrelinhas do conteúdo. Logo, esses elementos se completam: forma e conteúdo. Além disto, concorda-se com Bauer e Gaskell (2013), os quais contribuem para o entendimento acerca da necessidade de se considerar, além do corpus, as suas condições de produção.

Esses quadros ( 1 e 2) podem servir como norte para as análises dos vestígios históricos, porém, não devem ser tomados como instrumentos enrijecidos, pois, ajustes e modificações são passíveis durante a localização das fontes, considerando as novas reflexões suscitadas. O momento de "garimpagem" de vestígios históricos demanda tempo e paciência, bem como, o período para analisá-los. Contudo, quando parar as buscas por fontes?

Pode-se considerar que o momento para encerrar a procura por fontes corresponde ao alcance do que Guerra (2012) chama de "representatividade social”. Este elemento não diz respeito a elevada quantidade de amostra, mas tem relação ao que seria mais representativo para responder à pergunta 
de pesquisa. Contudo, a definição de representatividade social precisa de critérios, pois não deve se restringir a subjetividade do pesquisador. Por exemplo: Um pesquisador não deve utilizar como critério de escolha de determinado lócus de pesquisa o simples fato de ser o mais próximo de sua residência.

A segunda matriz de análise proposta (Quadro 2) contém um exemplo adaptado da técnica de categorização. Esta técnica, segundo Bardin (2016, p. 201), "funciona por operações de desmembramento do texto em unidades, em categorias segundo reagrupamentos analógicos".

Franco (2008, p. 67) e Bardin (2016, p.149 e p. 150) apresentam os requisitos principais para a criação de categorias, a saber: 1. "Exclusão mútua" (cada elemento não pode ser utilizado em mais de uma categoria, para não haver ambiguidades no momento do cálculo), 2. "Homogeneidade" (um único princípio de classificação: cruzamento de um registro com uma dimensão de análise), 3. "Pertinência" (intenções da investigação, com a definição de material de análise e quadro teórico), 4. "Objetividade e fidedignidade” (a aplicação de uma mesma grade categorial nas diversas partes de um material que será utilizado, além de deixar explícito os índices que determinam a entrada de determinado elemento em uma categoria) e 5. "Produtividade" (resultados de análise férteis, refletidos em inferências, hipóteses novas e "dados exatos").

É possível que algumas expressões utilizadas por Bardin (2016), tais como "dados exatos", incomodem algumas vertentes das pesquisas qualitativas, pois podem soar como positivista. Todavia, as características apresentadas acima correspondem aos critérios utilizados pela autora na sistematização de suas técnicas de análises. De forma similar, é válido ressaltar que toda pesquisa científica precisa indicar os seus critérios de cientificidade, independentemente se está atrelada à vertente que considera a subjetividade e relatividade ou se está excluindo-as e focando no distanciamento entre pesquisador e objeto de estudo.

As hipóteses refutadas na análise das fontes não desqualifica o trabalho acadêmico. Ao contrário, revela os caminhos de construção dos 
saberes; por isso, no Quadro 2, além de mostrar as categorias finais ( $a$ posteriori), também, optou-se por considerar as categorias a priori (surgidas antes de ir à campo).

Nesse trilhar nas análises de fontes, a informática pode ser uma aliada para catalogação e classificação dos dados. Atualmente há diversos softwares voltados para as técnicas de análises de conteúdo, a saber: ManyEyes, WebQDA, Alceste, ATLAS.ti, entre outros. Dentre as diversas possibilidades com o uso desses softwares está a realização de cálculos estatísticos, indicação de frequências, organização de temas, disposição de diversos formatos de apresentação dos dados. Entretanto, exige-se o conhecimento prévio de como se utilizar os programas, que nem sempre estão disponíveis em língua portuguesa.

Mesmo diante das possibilidades com o uso da informática, alguns estudiosos destacam a necessidade de certa cautela:

É necessário, contudo, uma palavra de precaução. Seria desastroso cair na armadilha do mito computador, um pressuposto de que pacotes de software irão substituir as habilidades e sensibilidades do pesquisador. Os computadores não farão nunca o trabalho intuitivo e criativo que é a parte essencial da análise qualitativa. No máximo, eles irão apoiar o processo e oferecer uma representação do resultado da análise (BAUER e GASKELL, 2013, p. 88)

Portanto, seja qual for a escolha do pesquisador: ferramentas manuais ou digitais, para a análise de dados, as técnicas de Análises de Conteúdos podem ser consideráveis aliadas no caminhar pela radiografia das fontes.

\section{CONSIDERAÇÕES FINAIS}

À guisa de considerações finais, retoma-se o questionamento inicial: Como dialogam Escola dos Annales e Análise de Conteúdo? - Nesse caso, a preocupação primordial está no processo, para além de se afirmar 
pontualmente se existe ou não a possibilidade do diálogo. Isso remete ao que Bardin (2016, p. 217) chama de "Palavra em ato", ao se referir à Técnica de Enunciação, a qual "apoia-se numa concepção da comunicação como processo e não como dado".

Nesse trilhar, que foca no entendimento do processo de relações entre uma abordagem metodológica (Escola dos Annales) e uma técnica de análise de dados (Análise de Conteúdo), compreende-se que há possibilidade de diálogo entre ambos. Muito mais do que colocar as semelhanças referentes ao seu local de origem (França), o artigo destacou aproximações e complementaridades do ponto de vista epistemológico. Além disso, foram sublinhados elementos que permeiam as resistências, desconfianças e oposições, por parte de algumas vertentes de pesquisas qualitativas, no uso das técnicas de Análises de Conteúdo.

A Escola dos Annales tem como característica a oposição à lógica positivista e historicista, porém, sem romper por completo com essas vertentes. Seriam as chamadas "oposições interativas", como denominara Barros (2010, p. 83 e p, 84). De modo geral, este movimento histórico tem como preocupação: história-problema, diálogo entre disciplinas, reflexão sobre o caráter das fontes e nova concepção de tempo.

Acerca das possibilidades de uso das Análises de Conteúdo, concordase com Bardin (2016, p. 38), para a qual "[...] o campo de aplicação é extremamente vasto. Em última análise, qualquer comunicação, isto é, qualquer veículo de significados de um emissor para um receptor, controlado ou não por este, deveria poder ser escrito, decifrado pelas técnicas de análise de conteúdo" (BARDIN, 2016, p. 38).

Partindo-se do princípio de diálogo entre História e as demais ciências, é válido destacar que, conforme Aróstegui (2006, p. 515), o foco das pesquisas de natureza qualitativa é o verbal; porém, para a apropriação ou interpretação do verbal não há impedimento do uso de técnicas "matematizadas" ou que dispõem do auxílio da informática. No contexto de cooperação, “a filologia e a história têm agido em colaboração há muito 
tempo" (ARÓSTEGUI, 2006, p. 524) e dentre as técnicas vinculadas a filologia, está a Análise de Conteúdo (idem, 2006, p. 518).

O diálogo entre História e demais ciências, defendida por Aróstegui (2006) vai na contramão da transversalidade, pois parte do princípio de hierarquia. Para o referido autor, a técnica escolhida para análise de dados está subordinada à abordagem metodológica da pesquisa.

Para além de hierarquizar, a discussão aqui proposta traz possibilidades de diálogo entre a abordagem teórico metodológica de uma pesquisa histórica e uma técnica de análise de dados, cuja gênese compõe ações de contagem de frequência, mas que não se restringem a elas. Logo, tem-se em vista a superação de compartimentalização do saber.

Diante do exposto, é válido ressaltar que o diálogo entre história e as demais ciências, também, é uma discussão necessária para se colocar em pauta nos Programas de Pós-graduação em Educação, valorizando, inclusive, as pesquisas históricas e/ou historiográficas.

Algo que serviu como alerta em relação ao cuidado com vestígios históricos foi o ocorrido em 2 de setembro de 2018: incêndio do Museu Nacional do Rio de Janeiro. Nesse dia, provavelmente, ecoou nos corações dos brasileiros o seguinte grito: "Não deixemos a história morrer!". Que a valorização da história seja feita a cada dia e não um lamento, após as tragédias que apagam os vestígios os quais possibilitariam a compreensão dos tempos que passaram!

Por fim, é singular observar a afirmativa do escritor tcheco Kundera (1978): "Para liquidar os povos, começa-se por lhes tirar a memória. Destroem-se seus livros, sua cultura, sua história. E uma outra pessoa lhes escreve outros livros, lhes dá outra cultura e lhes inventa uma outra história."

\section{REFERÊNCIAS}

ARÓSTEGUI, J. A pesquisa histórica: teoria e método. Tradução: Andréa Dore; revisão técnica José Jobson de Andrade Arruda. Bauru, SP: Edusc, 2006. $592 \mathrm{p}$.

Filos. e Educ., Campinas, SP, v.11, n.2, p.324-341, maio/ago. 2019 - ISSN 1984-9605 
ARRUDA, J. J. de Andrade. Apresentação. In: ARÓSTEGUI, J. A pesquisa histórica: teoria e método. Tradução: Andréa Dore; revisão técnica José Jobson de Andrade Arruda. Bauru, SP: Edusc, 2006. 592 p.

BACHELARD, Gaston. A Formação do Espirito Científico: contribuição para uma psicanálise do conhecimento. Rio de Janeiro: Contraponto, 2005.

. Uma epistemologia histórica. In: Epistemologia. Rio de Janeiro: Zahar, 1977

Conhecimento comum e conbecimento científico. In: Tempo Brasileiro São Paulo, n. 28, p. 47-56, jan-mar 1972.

. O novo espirito cientifico. Lisboa: Edições 70, 1996.

BARDIN, L. Análise de Conteúdo. Tradução: Luís Antero Reto, Augusto Pinheiro. São Paulo: Edições 70, 2016.

BARROS, J. D'Assunção. Historicismo: notas sobre um paradigma. ANTÍTESES, v. 5, n. ${ }^{\circ}$ 9, p. 391-419, jan/jul 2012.

A Escola dos Annales e a Crítica ao Historicismo e ao Positivismo. Revista Territórios e Fronteiras. v.3, n.1 - Jan/Jun 2010-a.

A Escola dos Annales: considerações sobre a história do movimento. Revista História em Reflexão: vol. 4 n. 8 - UFGD - Dourados jul/dez 2010-b.

BAUER, M. W.; GASKELL, G. Pesquisa Qualitativa Com Texto Imagem e Som. 11ed. Petrópolis, RJ: Vozes, 2013

BIBLIA SAGRADA. Traduzida em português por João Ferreira de Almeida. Revista e Atualizada no Brasil. 2 ed. Barueri - SP: Sociedade Bíblica do Brasil, 1993. 1248 p.

BLOCH, M. L. B. Apologia da História on o ofício de historiador. Prefácio de Jacques Le Goff; apresentação à educação brasileira de Lilia Moritz Schwarcz e tradução de André Telles. Rio de Janeiro: Jorge Zahar Ed, 2001.

FRANCO, M. L. P. B. Análise de Conteúdo. Brasília: Líber Livro Editora, 2008 .

Filos. e Educ., Campinas, SP, v.11, n.2, p.324-341, maio/ago. 2019 - ISSN 1984-9605 
GALLO, S. Conbecimento, transversalidade e currículo. In: REUNIÃO ANUAL DA ANPED, 24. Programa e resumos. Associação Nacional de PósGraduação e Pesquisa em Educação, 1995. Disponível em: < www.ia.ufrri.br/ppgea/conteudo/T1SF/Akiko/07.doc, >. Acesso em: 15 nov. 2018.

GAMBOA, S. S. Pesquisa em Educaşão: métodos e epistemologias. 2018.

GUERRA, I. C. Pesquisa Qualitativa e Análise de Conteúdo: sentidos e formas de uso. Princípia, 2012.

KUNDERA, M. O Livro do Riso e do Esquecimento, 1978.

JAPIASSU, H. Introdução ao pensamento epistemológico. Rio de Janeiro: Francisco Alves, 1986.

LOPES, A.R. C. Bachelard: o filósofo da desilusão. Caderno Brasileiro de Ensino de Física, v.13, n.3, p248-273, 1996.

MONTEIRO, L. A.; MUNHOZ, Daniella; BERTHOLINI, F. Bachelard e a Epistemologia Histórica: uma vivência sobre a formação do espírito científico. XXXVI Encontro da ANPAD. Rio de Janeiro/ RJ - 22 a 26 de Setembro de 2012. Disponível em: < $\underline{\text { https://docplayer.com.br/35893902-Bachelard-e-a- }}$ epistemologia-historica-uma-vivencia-sobre-a-formacao-do-espiritocientifico.html>. Acesso em: 22 mar. 2019.

REIS, José Carlos. Nouvelle Histoire e Tempo Histórico. São Paulo: Ática, 1994.

Submetido em: $24 / 03 / 2019$

Aceito em: 23/03/2020

Publicado em: 27/03/2020

Filos. e Educ., Campinas, SP, v.11, n.2, p.324-341, maio/ago. 2019 - ISSN 1984-9605 